\title{
Macroclimate and viticultural zoning in Europe: observed trends and atmospheric forcing
}

\author{
João A. Santos ${ }^{1, *}$, Aureliano C. Malheiro ${ }^{1}$, Joaquim G. Pinto ${ }^{2}$, Gregory V. Jones ${ }^{3}$ \\ ${ }^{1}$ Centre for Research and Technology of Agro-Environment and Biological Sciences (CITAB), \\ University of Trás-os-Montes e Alto Douro, PO Box 1013, 5001-801 Vila Real, Portugal \\ ${ }^{2}$ Institute for Geophysics and Meteorology, University of Cologne, Kerpener Str. 13, 50923 Cologne, Germany \\ ${ }^{3}$ Department of Environmental Studies, Southern Oregon University, 1250 Siskiyou Boulevard, Ashland, Oregon 97520, USA
}

\begin{abstract}
Temperature and precipitation are major forcing factors influencing grapevine phenology and yield, as well as wine quality. Bioclimatic indices describing the suitability of a particular region for wine production are a commonly used tool for viticultural zoning. For this research these indices were computed for Europe by using the E-OBS gridded daily temperature and precipitation data set for the period from 1950 to 2009. Results showed strong regional contrasts based on the different index patterns and reproduced the wide diversity of local conditions that largely explain the quality and diversity of grapevines being grown across Europe. Owing to the strong inter-annual variability in the indices, a trend analysis and a principal component analysis were applied together with an assessment of their mean patterns. Significant trends were identified in the Winkler and Huglin indices, particularly for southwestern Europe. Four statistically significant orthogonal modes of variability were isolated for the Huglin index (HI), jointly representing $82 \%$ of the total variance in Europe. The leading mode was largely dominant $(48 \%$ of variance) and mainly reflected the observed historical long-term changes. The other 3 modes corresponded to regional dipoles within Europe. Despite the relevance of local and regional climatic characteristics to grapevines, it was demonstrated via canonical correlation analysis that the observed inter-annual variability of the HI was strongly controlled by the large-scale atmospheric circulation during the growing season (April to September).
\end{abstract}

KEY WORDS: Viticultural zoning · Europe $\cdot$ Huglin Index · Winkler Index · Historical trends · Variability $\cdot$ Atmospheric forcing $\cdot$ E-OBS

\section{INTRODUCTION}

Climate, one of the main factors controlling grapevine yield and quality for a given region (e.g. van Leeuwen et al. 2004, Santos et al. 2011), can directly and indirectly affect vine physiology, growth and stages of development (Magalhães 2008). In fact, regardless of all technical and scientific achievements (e.g. better plant material, more efficient vine training systems, better management of water supply by irrigation, genetic manipulation), Vitis vinifera L., re- mains a demanding species that requires a suitable climate for adequate and economically sustainable development.

Winegrapes are traditionally grown in geographical regions where the mean temperature during the growing season (April to October for the Northern Hemisphere) is within 12 to $22^{\circ} \mathrm{C}$ (Jones 2006). Furthermore, local and regional atmospheric forcing have an important influence on grapevine phenology (Jones \& Davis 2000a), yield (Bindi et al. 1996, Santos et al. 2011) and wine quality (Rodó \& Comín 2000, 
Esteves \& Orgaz 2001, Grifoni et al. 2006, Orlandini et al. 2009) in different European regions. As an illustration, high correlations between grapevine yield and mean large-scale atmospheric patterns in March, May and June (from budburst to berry set) were found for the Douro Region, Portugal (Santos et al. 2011). Similar results were obtained for Bordeaux, France, where enhanced frequency of anticyclonic systems (warm and dry conditions) during flowering and berry set promotes higher wine production. Conversely, an increased occurrence of low pressure systems (wetter und unsteady conditions) during those stages was shown to reduce yield and quality (Jones \& Davis 2000b). Also, grapevines can be severely damaged under extremely high or low temperatures (Hidalgo 2002), and despite their relatively high tolerance to drought, they can also be negatively affected by extremely dry conditions (Koundouras et al. 1999, dos Santos et al. 2003).

Relationships between the North Atlantic Oscillation (NAO) and winegrape production in Europe are not clear, and most studies show little to no correlation (e.g. Jones 1997). This is probably because the NAO is largely a wintertime mechanism and its effects diminish over the summer half of the year (e.g. Wanner et al. 2001). The strength of this connection is further reduced when the NAO index is averaged over the growing seasons. However, some studies suggest that a dominantly positive NAO phase during the growing season results in lower winegrape quality and yield in the Iberian Peninsula and the Mediterranean, mainly owing to the associated drier conditions (Esteves \& Orgaz 2001, Grifoni et al. 2006). For the vineyards in northern Europe either phase can be problematic: while a positive NAO brings wetter conditions and greater disease pressure, a negative NAO phase brings greater frost pressure during spring. Nevertheless, Souriau \& Yiou (2001), using historical grape harvest dates from northeastern France and Switzerland, showed significant correlations between harvest dates and the NAO and suggested using the record 'as an interesting proxy' to reconstruct the NAO back to the late Middle Ages.

Given the sensitivity of grapevines to climate, long-term trends such as a $0.6^{\circ} \mathrm{C}$ increase in mean surface temperature since the nineteenth century (Trenberth et al. 2007) also have probably influenced wine production. In fact, recent research focusing specifically on wine regions has found a mean increase in growing season temperatures (GST) of $1.26^{\circ} \mathrm{C}$ over the last $50 \mathrm{yr}(1950-1999)$ in 27 regions worldwide (Jones et al. 2005a). For Europe,
Jones et al. (2005b) found GST warming of $1.7^{\circ} \mathrm{C}$ (averaged over 9 wine regions) during 30-55 yr periods from approximately 1950 to 2004. Changes of this magnitude have resulted in earlier phenological events and/or changes in yield and wine characteristics, as well as in altering the geographical distribution of where grapevines can be grown (Kenny \& Harrison 1992, Schultz 2000, Jones et al. 2005b).

Considering the interactions between the climatic requirements for grapevines and their growing cycle, several bioclimatic indices have been proposed to describe the suitability of different wine growing areas. Such bioclimatic indices describe the suitability of a particular region for wine production and are widely used as a zoning tool. From among the bioclimatic indices commonly used for viticultural zoning in Europe, the following were selected for the present study: growing season suitability, number of days with minimum temperature below $-17^{\circ} \mathrm{C}$, cool night index, growing season precipitation, the Branas-Bernon-Levadoux, dryness, Winkler and Huglin indices (e.g. Tonietto \& Carbonneau 2004, Jones et al. 2010) and a composite index (Malheiro et al. 2010). In addition to climatological factors, the suitability for wine production of a given region also depends upon non-atmospheric factors, such as landscape, soil characteristics and the grape cultivar that is planted (van Leeuwen et al. 2004). For instance, in northeastern Spain, land transformations to adapt vineyards to mechanization may represent an important feedback in suitability by negatively affecting water availability and yield (Ramos 2006). Such factors are, however, not considered here as this research focuses solely on atmospheric factors.

In the present study a new high resolution data set was used for 1950-2009 to examine recent past spatial distributions, variability, and trends in viticultural suitability in Europe. The study had 2 principal aims. (1) To obtain detailed maps of a set of bioclimatic indices for Europe, which would provide updated information for viticultural zoning. With this aim, several indices were considered to isolate the most suitable regions for winegrape production (viticultural zoning) and the results were compared with previous studies. (2) To identify spatial and temporal changes in the indices. For this purpose, multivariate statistical techniques were applied to help isolate significant modes in the spatial-temporal variability of the bioclimatic indices. Finally, these modes were related to large-scale atmospheric circulation, which would provide insights into the atmospheric mechanisms that influenced the underlying inter-annual variability in the bioclimatic indices for Europe. 


\section{DATA AND METHODS}

Gridded daily precipitation totals and daily minimum, mean and maximum air temperatures over Europe were used for the bioclimatic index calculations. The ENSEMBLES observational gridded data set for Europe (E-OBS) from the EU-FP6 project ENSEMBLES (http://ensembles-eu.metoffice.com) was provided by the European Climate Assessment and Dataset (ECA\&D) project (http://eca.knmi.nl). The full available period was selected for this study (1950-2009, 60 yr). The original gridded data is defined over land areas and over a grid with 201 latitudes and 464 longitudes $\left(0.25^{\circ}\right.$ latitude $\times 0.25^{\circ}$ longitude). Further details about this data set are described by Haylock et al. (2008).

Since the present study focuses on viticulture zoning in Europe, only the following geographical region was taken into account in the subsequent index calculations: $34.875^{\circ} \mathrm{N}$ to $60.125^{\circ} \mathrm{N}, 10.625^{\circ} \mathrm{W}$ to $38.125^{\circ} \mathrm{E}$ (see Figs. 1-8). This subsector has 102 latitudes $\times 196$ longitudes, with data from most of the continental areas; grid boxes without available data are represented in white (see Fig. 1). The daily grids over the 60 yr time period were processed into the bioclimatic indices, plotted as average field maps and assessed with various statistical tools (see below). Growing season suitability (GSS; fraction of days in April-September with daily mean air temperature above $10^{\circ} \mathrm{C}$ ) and growing season precipitation (GSP; Blanco-Ward et al. 2007) are basic indices for general suitability use in viticultural zoning in Europe. Additionally, the occurrence of temperatures below $-17^{\circ} \mathrm{C}$, which is commonly considered a lethal lower temperature limit for Vitis vinifera (Hidalgo 2002), is a very important constraint for grapevine growing. Finally, the cool night index $\left(\mathrm{CI}_{i}\right.$ Tonietto \& Carbonneau 2004), which accounts for minimum temperatures during grape maturation (average minimum air temperature in September), is also considered.

The Winkler index (WI; Winkler et al. 1974, Jones et al. 2010) and the Huglin index (HI; Huglin 1978), the hydrothermic index of Branas-Bernon-Levadoux (HyI Branas et al. 1946) and the dryness index (DI; Riou et al. 1994, Tonietto \& Carbonneau 2004) are more complex bioclimatic indices. In general, the WI and $\mathrm{HI}$ are heat accumulation or degree-day indices that are both commonly used in viticulture zoning studies (Jones et al. 2010). The HyI and DI are index measures that capture moisture surplus or deficit issues and have also been used in viticulture zoning studies (e.g. Blanco-Ward et al. 2007). Further information regarding these indices can be found in Toni- etto \& Carbonneau (2004), Jones et al. (2010) and Malheiro et al. (2010). The maps of these indices (see Figs. 1-3) are plotted by using classes based on previous studies (see captions).

The composite index (CompI) developed by Malheiro et al. (2010) is also applied in the present study. However, some modifications in the index limits were performed to obtain patterns that more closely reflected the actual distribution of viticultural regions in Europe. The CompI combines aspects of the other indices whereby composite suitability for a specific year ('optimal year') depends upon sufficient heat accumulation ( $\mathrm{HI} \geq 1200$, instead of 1400 as in Malheiro et al. 2010), moderate drought stress (DI $\geq-100$ ) and low risk of winter extreme temperatures $\left(<-17^{\circ} \mathrm{C}\right)$ simultaneously. The criterion for risk of downy mildew disease owing to the combined effects of temperature and precipitation is not taken into account here, as the literature-based limit for the $\mathrm{HyI}\left(<5100^{\circ} \mathrm{C} \mathrm{mm}\right)$ is too restrictive (not shown) and contributes to unrealistically low CompI values for several established viticultural regions in France and Germany. CompI is simply the fraction of 'optimal years' at a given location (dimensionless measure ranging from 0 to 1 ). For instance, a CompI of 0.5 implies that $50 \%$ of the years have ideal conditions of heat accumulation, moderate drought stress and low risk of winter freezes for optimum grapevine growing conditions.

Principal component analysis (PCA) is a widely applied multivariate statistical approach in atmospheric sciences and climate research (see Wilks 2006). The aim of PCA is to reduce the dimensionality of a given space-time field: a new set of mutually independent variables (principal components, $\mathrm{PCs}$ ) is obtained from linear combinations of the original variables (projected onto a set of empirical orthogonal functions, EOFs). The first few modes typically represent the majority of the variability in the system, effectively reducing the number of variables to a few significant modes of variability that can be retained for further analysis. The statistical significance of the orthogonal modes can be assessed through North's rule of thumb (North et al. 1982). The mutual orthogonality of the EOFs is also a major advantage of PCA, as different modes of variability are independent and can be related to independent forcing mechanisms.

The establishment of relationships between the inter-annual variability of the bioclimatic indices and the large-scale atmospheric circulation was addressed by computing modes of coupled variability between the indices and 2 large-scale atmospheric fields, namely the $2 \mathrm{~m}$ air temperature and mean sea level pressure (MSLP). Atmospheric fields are ob- 
tained from the National Centers for Environmental Prediction and National Center for Atmospheric Research (NCEP/NCAR) reanalysis (see Kistler et al. 2001). This data set has global coverage, with a spatial resolution of $2.5^{\circ}$ latitude $\times 2.5^{\circ}$ longitude, and a temporal resolution every $6 \mathrm{~h}$. The $2 \mathrm{~m}$ air temperature and MSLP are considered for the period 1955-2009.

Modes of coupled variability can be isolated by applying a canonical correlation analysis (CCA). The approach proposed by Barnett \& Preisendorfer (1987) was followed here. In this approach, the CCA was combined with the PCA in such a way that only the first leading PCs of each of the 2 fields were retained for CCA (retained PCs must cumulatively explain 70 to $80 \%$ of the total variance of each field; truncation criterion for CCA). A detailed discussion of this method can be found, for example, in Bretherton et al. (1992). Previous studies have successfully applied this methodology in isolating large-scale coupled modes for temperature and precipitation in Europe (e.g. Santos \& Corte-Real 2006, Santos et al. 2007).

Despite of the relatively coarse grid, the NCEP data allowed a suitable analysis of the large-scale atmospheric flow patterns. As the purpose of this study was to isolate large-scale features in the atmospheric circulation coupled with the inter-annual variability of the indices, the multivariate techniques used here were specifically devoted to isolate large-scale modes of variability, not to capture small-scale details. Hence, the use of reanalysis data sets with higher spatial resolution (e.g. ERA-40, ERA-Interim or JRA reanalysis) is not an advantage. Further, such data sets have shorter time periods and would significantly limit the comparability with the E-OBS data set.

Since data availability in the E-OBS data set depends on the atmospheric variable, the number and location of the blank grid boxes ('white cells') also depended on the index. Although some grid boxes had missing data, most of these data gaps occurred at the very beginning of the time series (1950-1954), and only over parts of Italy, Greece, Turkey, Cyprus, Algeria and Tunisia. As the replacement of missing data may have brought important uncertainties to the analysis, the bioclimatic indices for all years with missing data were not taken into account in the computation of the mean patterns (see Figs. 1-4). In this way, the maps provided as much information as possible. Nonetheless, the same procedure could not be applied to the PCA and CCA, since these multivariate techniques required a common period without missing data. As such, the sub-period from 1955 to 2009 was selected for these latter analyses, enabling the inclusion of almost all land areas (see Figs. 5, 7 \& 8).
In the present study, PCA was applied to the HI in Europe (196 longitudes $\times 102$ latitudes = 19992 grid boxes) for 1955-2009 (55 yr); all blank and missing data grid boxes within this time period were removed from the analysis, resulting in a total of 11870 grid points. The covariance matrix for the selected grid boxes was computed and PCA was directly applied to this matrix. The covariance fields between the normalized PCs (scores) and the HI field yielded the spatial patterns of the EOFs (loadings) in ${ }^{\circ} \mathrm{C} \mathrm{SD}^{-1}$. The CCA was then applied between the leading PCs of both the NCEP/NCAR reanalysed air temperature/ MSLP and the HI in Europe. Reanalysis data was selected only within the Euro-Atlantic sector (20$\left.70^{\circ} \mathrm{N}, 60^{\circ} \mathrm{W}-60^{\circ} \mathrm{E}\right)$. After the cross-covariance matrices between these PCs were computed, their singular value decompositions were performed, which yielded the canonical variables. The pairs of canonical patterns for each mode corresponded to covariance patterns between the pair of normalized canonical variables for that mode and the respective fields.

\section{RESULTS}

\subsection{Mean patterns and trends}

The mean patterns of the GSS and GSP highlight the main climatic zones in Europe and emphasise those zones more relevant to winegrape growing (Fig. 1a,b). From a strictly thermal viewpoint, a given region can be considered suitable for grapevine growing when daily mean temperatures above a base temperature (Amerine \& Winkler 1944, Winkler et al. 1974) are predominant during the growing season (April to September for Europe). Temperatures above $10^{\circ} \mathrm{C}$ are necessary for grapevines to be physiologically active. Hence, regions where at least $90 \%$ of the days meet this basic thermal requirement tend to be the most suitable for wine production. This is the case for large areas of the Iberian Peninsula, the Balkan Peninsula (including Hungary), the Black Sea coastal areas and much of France and Italy, where world renowned wine producing regions are found. However, several areas in western Europe where vineyards are grown (e.g. Burgundy, Champagne and the Mosel and Rhine valleys of Germany) have a GSS between 80 and $90 \%$ of the days during the growing season. These areas are still suitable to viticulture, but are typically at higher latitudes or slightly higher elevations, where the growing season is shorter, frost risk is greater or climate variability is more pronounced. Nearly all areas with a GSS of less 

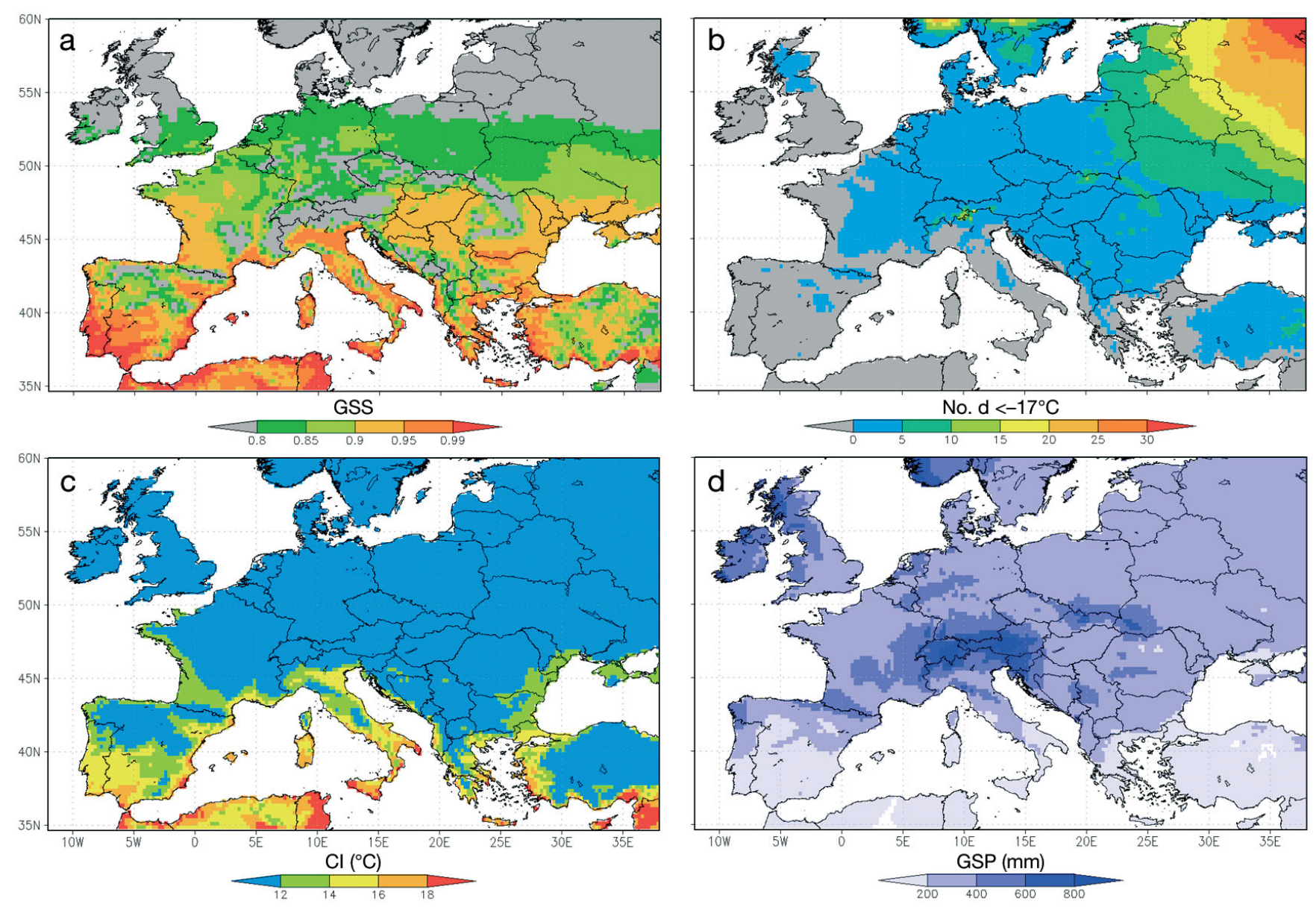

Fig. 1. (a) Mean pattern of the growing season suitability (GSS, fraction of days in April-September with daily mean air temperature equal to or above $10^{\circ} \mathrm{C}$ ). (b) Annual mean number of days with minimum temperature below $-17^{\circ} \mathrm{C}$. (c) Mean pattern of the cool night index (CI), (d) Mean pattern of the growing season precipitation (GSP, April-September). All maps refer to 1950-2009 (E-OBS data set)

than $80 \%$ are high altitude or latitude zones that are typically not suitable to viticulture.

The occurrence of daily minimum temperatures below $-17^{\circ} \mathrm{C}$ is a very important limitation for grapevine growing over large areas of eastern Europe (Fig. 1b), where more than 5 annual occurrences are observed. On the other hand, the cool night index mean pattern highlights that some Mediterranean coastal areas record relatively high values, in some cases above $18^{\circ} \mathrm{C}$ (Fig. 1C). These higher nocturnal temperatures during ripening can have detrimental effects on the production of high quality wines, although this effect is also dependent on diurnal temperatures and on grape variety (Kliewer \& Torres 1972). Cool nights during ripening also can enhance aroma, flavour and overall quality (Tonietto \& Carbonneau 2004).

Several technological solutions have been developed to overcome humidity and precipitation effects and/or limitations, e.g. irrigation techniques for low precipitation areas and use of fungicides to control diseases such as downy mildew, which may be induced by exposure of grapevines to moisture. However, the GSP is still an important factor when assessing the suitability and economic viability of a given region for grapevine growing and wine production. Large areas of central Europe might be considered excessively humid and rainy (GSP over $600 \mathrm{~mm}$ ), while some parts of southern Europe might be excessively dry (GSP below $200 \mathrm{~mm}$ ), particularly some regions in the southern Iberian Peninsula, southern Italy and Greece (Fig. 1d). However, these precipitation features need to be substantiated by adequate indices with predefined thresholds (e.g. HyI and DI), as there are no precise limits for precipitation in defining viticultural zones. The HyI (Branas et al. 1946) provides further insight into moisture issues depicting values above $5100^{\circ} \mathrm{C} \mathrm{mm}$ (high risk of 
downy mildew disease) over large areas of central Europe and values below $2500^{\circ} \mathrm{C} \mathrm{mm}$ (low risk of downy mildew disease) over the southern and central Iberian Peninsula, southern Italy and Greece (Fig. 2a). The north-south gradient in growing season precipitation is also apparent in the DI, with values greater than $100 \mathrm{~mm}$ over most of the mid-latitudes of Europe and negative values over southern Iberian Peninsula. Taken together, the temperature and precipitation fields in Europe, with their sharp and opposite north-south gradients, create strong heterogeneity of local conditions that largely explain the diversity (cool versus warm growing conditions) and variation in quality of the European wines.

When the updated classes given by Jones et al. (2010) are used, the WI and HI present very similar patterns, although with slightly different magnitudes owing to the higher weighting that the HI has for maximum temperatures (Fig. 3a,c). Based on these patterns, most of the Iberian Peninsula is suitable for grapevine growing with the exception of regions found in high altitudes and some northern areas; the north-south contrast is still noteworthy and underlies the diversity of grapevine varieties grown in the Iberian Peninsula and the numerous types of wine produced. Most of France is also suitable, but with lower index values (cooler climate conditions). Apart from high-altitude areas, Italy and Greece also present high index values. In some regions of southwestern (e.g. Mosel Valley) and eastern Germany the index values are also clearly above the minimum threshold $\left(850^{\circ} \mathrm{C}\right.$ and $900^{\circ} \mathrm{C}$ for the WI and $\mathrm{HI}$, respectively), indicating some suitability for wine production. Large areas of Hungary, Romania, Moldova, southern Ukraine and the Balkan Peninsula also reveal a large number of potential wine producing regions. Most of the regions within the latitude belt of 50 to $53^{\circ} \mathrm{N}$ are also marginally suitable to grapevine growing, with values close to the minimum thresholds of both indices.

Although the previous climate-mean patterns are quite informative, some valuable information can also be obtained by assessing possible changes in the $\mathrm{HI}$ and WI over time. However, linear trend estimations are not suitable for this analysis, since, as will be shown below for the HI, the temporal evolution is far from being linear. Moreover, the normality assumption may not be fulfilled for the index distributions. Therefore, differences between the medians of each index are calculated over 2 independent time periods (1950-1979 and 1980-2009) and their statistical significances are assessed by applying the nonparametric Wilcoxon-Mann-Whitney test (Wilks
2006). For WI and HI, changes in medians clearly depict statistically significant increases (99\% confidence level) over most of Europe, particularly over the Iberian Peninsula, France and Italy (Fig. 3b,d). The changes in the HI are higher than in the WI and range from less than 100 units (WI or HI) in eastern Europe to over 200 units in numerous areas of the Iberian Peninsula, France and Italy; the higher trends in the $\mathrm{HI}$ result from the index weighting maximum temperatures greater than the WI formulation. These changes are a clear manifestation of the upward trends in the daily mean temperatures during the growing season (not shown). Because these 2 bioclimatic indices are values accumulated over the growing season, they represent an integrated seasonal warming signal over these regions.

\subsection{Composite index}

The CompI has already been successfully applied to Europe and has proven to be particularly useful in combining the heliothermal and hydrometric conditions for viticultural zoning purposes (Malheiro et al. 2010). The mean patterns of the CompI for 19502009 clearly depict the most suitable European regions for wine production (Fig. 4a): the Iberian Peninsula, France, Italy, Greece, Turkey, Hungary and some areas in Germany and the Balkan Peninsula. The southern portion of the Iberian Peninsula has CompI > 0.99, i.e. at least $99 \%$ of the years (1950-2009) are suitable (all the defined thresholds are met), which is being driven by a high $\mathrm{HI}$ and little cold pressure during the winter. Similar patterns can be seen for southern France, southern Italy and Greece. Furthermore, considering the differences of CompI between 1980-2009 and 1950-1979, there are clear upward trends over most of Europe (Fig. 4b), which are also largely in agreement with the identified changes in WI and HI (Fig. 3b,d). Therefore, during the period from 1950 to 2009 there has been an enhancement of the favourable conditions to grapevine growing throughout much of Europe (e.g. in large areas of France and Germany), little to no change in conditions in the Mediterranean areas (e.g. Italy and southern Iberian Peninsula) and only a few isolated areas of declining conditions (owing to excessive dryness; DI $<-100 \mathrm{~mm}$ ).

The values (ratios) of CompI also reflect an important measure of inter-annual variability, as at a given location only a fraction of years meet all the predefined thresholds (i.e. not all years are favourable). In fact, despite identifying significant changes between 

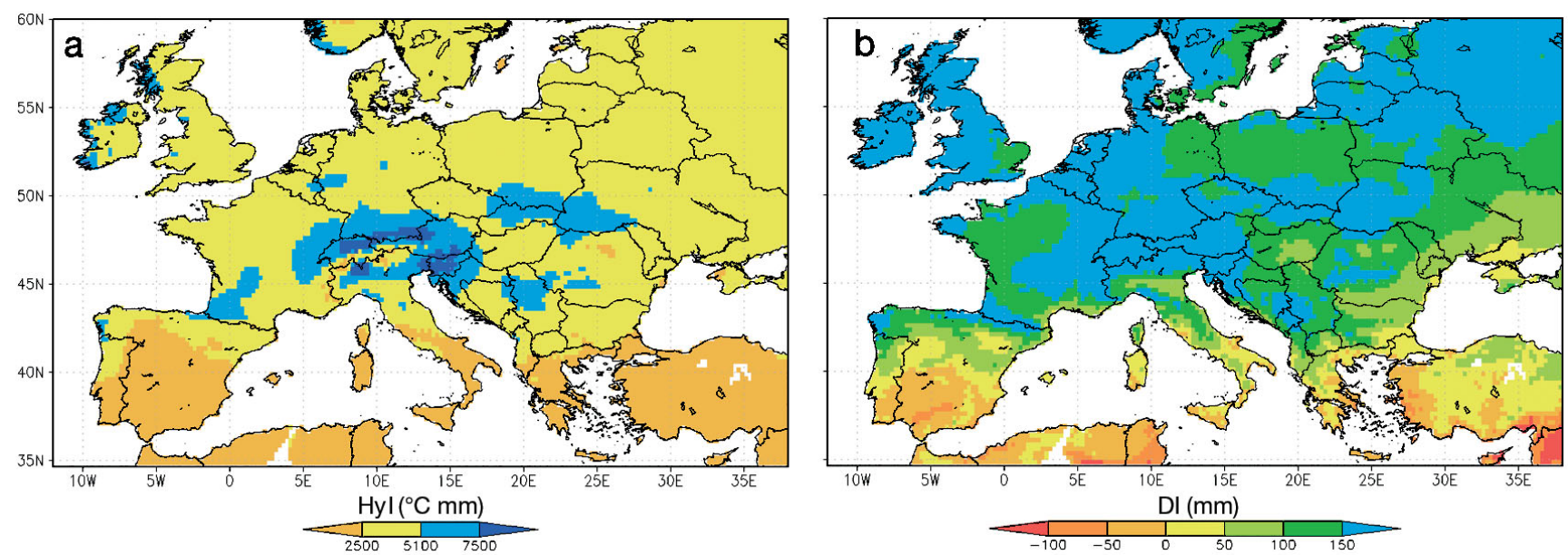

Fig. 2. (a) Mean pattern of the hydrothermic Branas-Bernon-Levadoux index (HyI) in 1950-2009 (E-OBS data set). Classes were considered according to Branas et al. (1946) with the additional class of $5100-7500{ }^{\circ} \mathrm{C}$ mm. (b) Mean pattern of the dryness index (DI) for the same period and data set
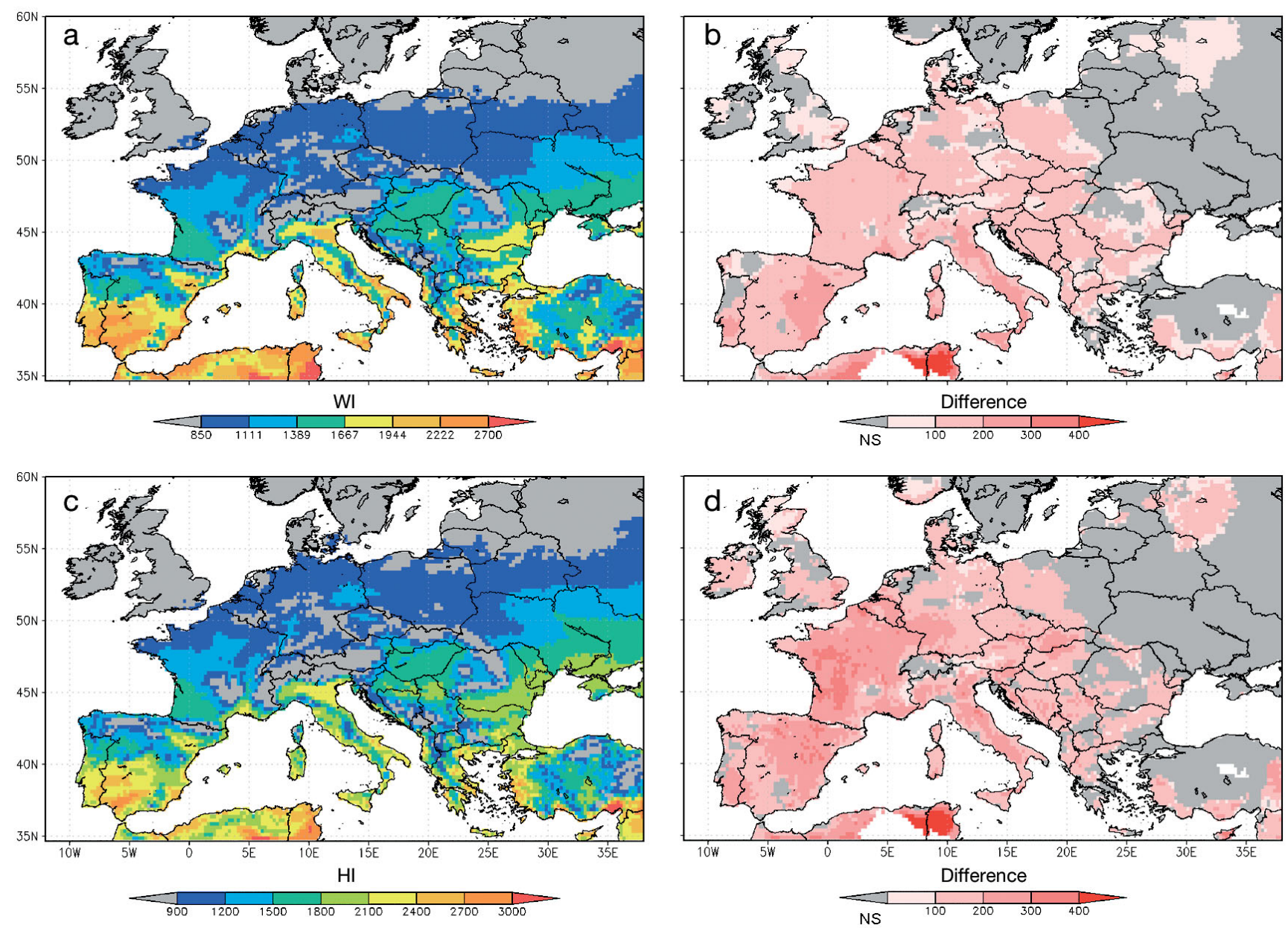

Fig. 3. (a) Mean pattern of the Winkler index (WI, growing degree-days in ${ }^{\circ} \mathrm{C}$ ) in $1950-2009$ (E-OBS data set). (b) Differences in the medians of the WI between 1980-2009 and 1950-1979 (Wilcoxon-Mann-Whitney test). Differences not statistically significant (NS) at the $99 \%$ confidence level are indicated by grey shading. (c,d) The same as described in panels (a) and (b) but for the Huglin index (HI, growing degree-days in ${ }^{\circ} \mathrm{C}$ ). Classes in both indices were based on those in Jones et al. (2010) with the additional class of 900-1200 in the HI 

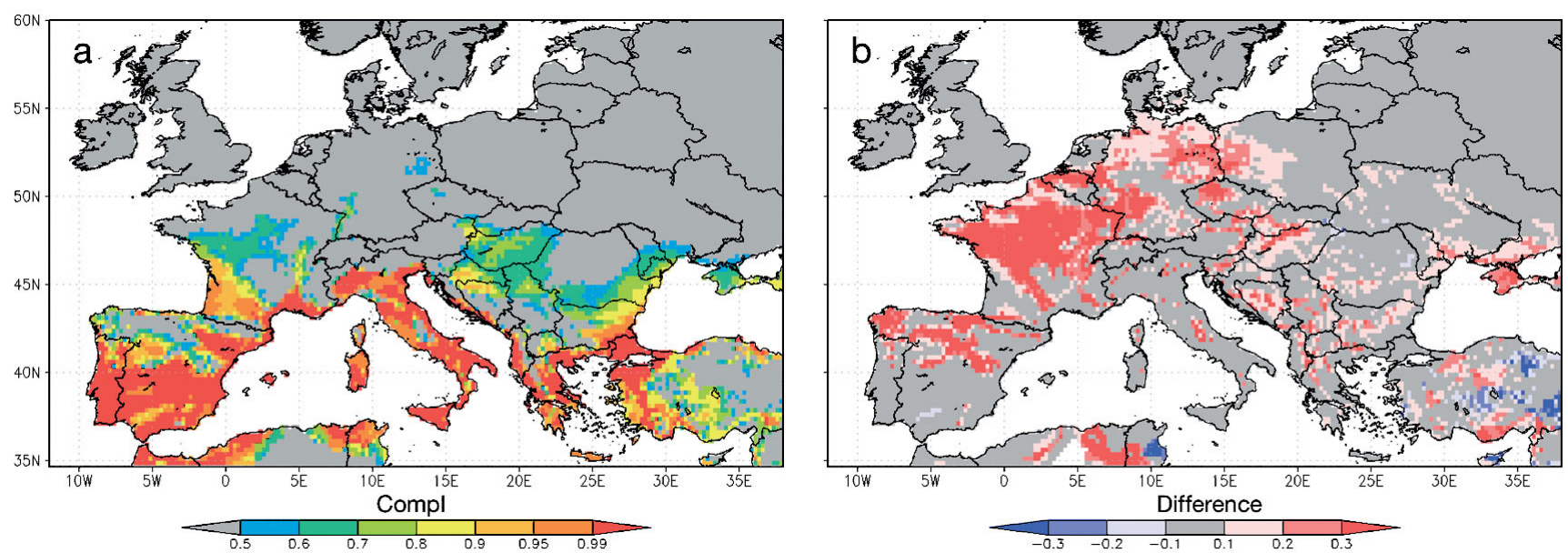

Fig. 4. (a) The composite index (CompI, see text for details) over Europe for the 1950-2009 period. Index values correspond to the fraction of years within the considered time period that are suitable for winegrape growing. (b) CompI difference: 1980-2009 minus 1950-1979 (first and second halves of the total period)

the 2 time periods, there is also an important interannual variability. This variability implies irregularity in the climatic conditions, which may have strong effects on grapevine growth, as well as on the fruit yield, wine quality and the economics of wine regions in Europe (i.e. the vintage effect). Therefore, the analysis of the temporal variability of the indices is also highly relevant for the wine sector in Europe. For the sake of succinctness only the HI is analysed here.

\subsection{Modes of inter-annual variability}

A PCA was applied to the annual fields (maps) of HI (1955-2009) to isolate the corresponding major orthogonal modes of spatial variability. The 4 leading modes are above the red noise level (mean eigenvalues of 100 covariance matrices generated by random permutations in time, independently performed at each grid box of the observed $\mathrm{HI}$ field) and are nondegenerate (North's rule, Wilks 2006), thus are retained (see eigenspectrum in Fig. 6a). They represent $82 \%$ of the total variance, which is in line with the truncation criterion for CCA (see Section 2). Their large-scale patterns suggest that the temporal variability of $\mathrm{HI}$ is strongly connected to the large-scale atmospheric circulation.

The spatial pattern of the first mode (Fig. 5a) represents $48 \%$ of the total variance and isolates a pattern that is remarkably similar to the $\mathrm{HI}$ trend pattern presented above (Fig. 3b; their spatial correlation is $\mathrm{r}=$ 0.79 , which is statistically significant at the $99 \%$ confidence level). The corresponding PC indeed pre- sents a strong upward trend, which is only almost linear since the late $1970 \mathrm{~s}$; however, its overall trend is better fitted by a second-order polynomial than by a linear trend model (Fig. 6b). The leading mode clearly reflects the recorded warming over Europe, particularly over its western and southern areas. The second mode (Fig. 5b) roughly explains $19 \%$ of the total variance and displays an approximate eastwest contrast in Europe. The third mode (Fig. 5c) explains about $9 \%$ of the total variance and represents a contrast between northern and western Europe and southeastern Europe. The fourth mode (Fig. 5d) represents $6 \%$ of the total variance and displays a strong phase opposition between central Europe and the Iberian Peninsula and Turkey.

Similar results were obtained for WI, though its first mode explains about $52 \%$ of the total variance; the other mode contributions to total variance are analogous and the corresponding EOF patterns are strikingly similar to the HI EOF patterns (not shown). Both bioclimatic indices have comparable temporal variability and underline the key role of the large-scale atmospheric forcing on viticultural suitability in a given region and for a specific year (or growing season). Further analysis highlighted a low sensitivity of these modes to linear detrending; the spatial patterns of the EOFs remain almost unchanged (not shown), while only small changes occur in the fractions of explained variance (for HI: 41, 21, 12 and $7 \%$ ). In fact, since the long-term trend is far from being linear (Fig. 6), removing linear trends will not significantly weaken the first mode, whereas the other 3 modes remain largely unaffected by linear trends. 

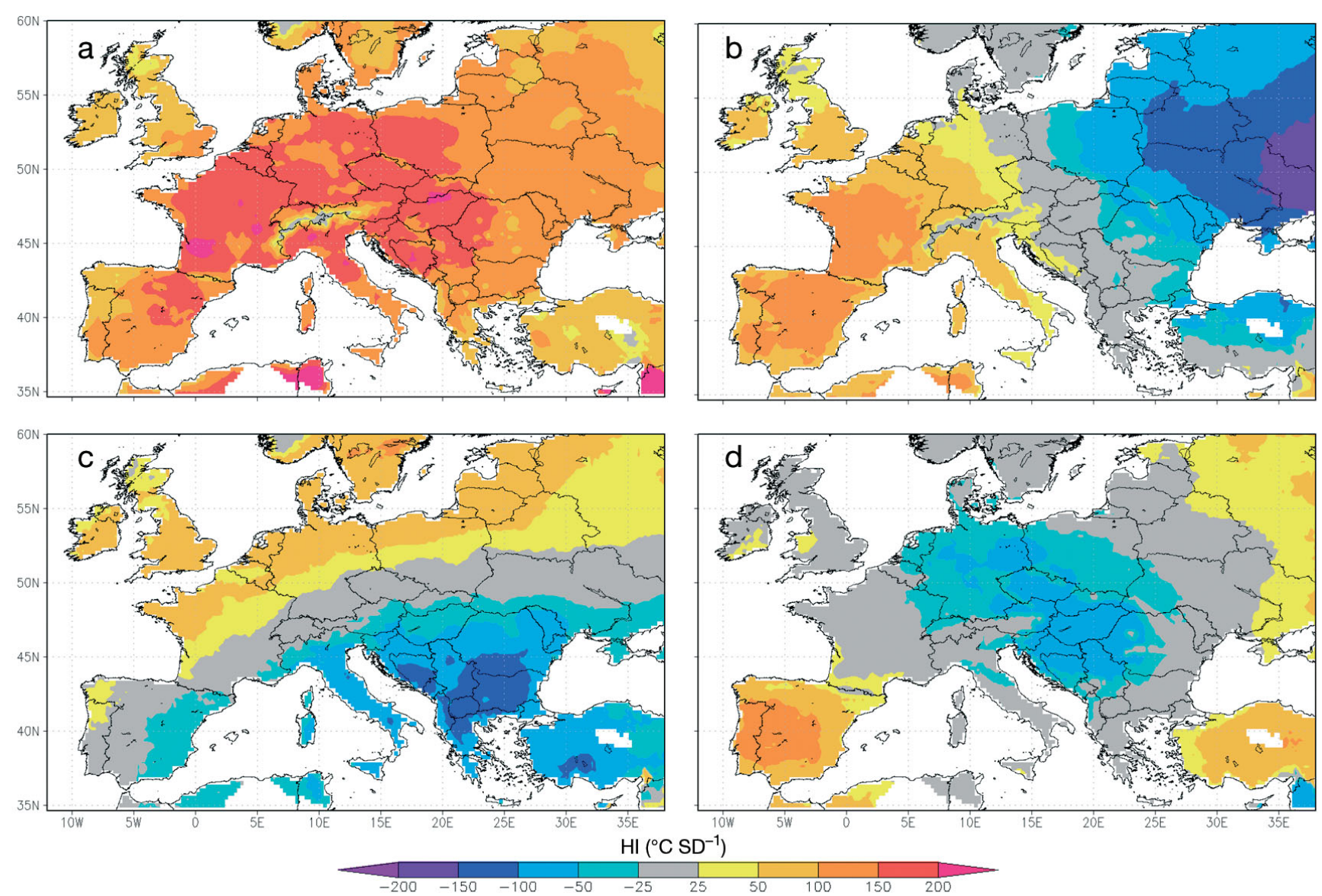

Fig. 5. Patterns of the (a) first, (b) second, (c) third and (d) fourth empirical orthogonal modes of the Huglin Index (HI) over Europe (E-OBS data set in 1955-2009), where SD is that of the respective principal component. These 4 principal components are significant, with percentages of represented variances of $48,19,9$ and $6 \%$, respectively

\subsection{Large-scale atmospheric forcing}

The large-scale patterns of the EOFs presented above suggest a strong connection between the HI and the large-scale atmospheric flow over the EuroAtlantic sector. As previously stated, the existence of possible couplings between the $\mathrm{HI}$ and the largescale circulation is demonstrated through the use of CCA. The leading 4 PCs of HI (Fig. 5) are retained for CCA ( $82 \%$ of represented variance), while the leading 8 PCs are retained for air temperature $(73 \%)$ and 6 PCs retained for sea level pressure $(78 \%)$; the truncation criterion referred to in Section 2 is then met. Hence, 4 coupled modes exist for each of the 2 analyses (air temperature and sea level pressure). According to the Bartlett-Lawley significance test (von Storch \& Zwiers 1999), the 4 coupled modes are significant at the $95 \%$ confidence level. By applying CCA between the $\mathrm{HI}$ and the $2 \mathrm{~m}$ air temperature, averaged over the growing season, the corresponding canonical pairs (coupled patterns/modes) were obtained (Fig. 7); left panels represent the canonical patterns in the air temperature, while right panels represent the associated canonical patterns in the HI.

Since the HI is based on the air temperature field, the 4 coupled patterns show a clear accordance between positive and negative temperature anomalies and positive and negative $\mathrm{HI}$ anomalies. Furthermore, the HI canonical patterns are largely consistent with the EOF patterns themselves (Figs. 5 \& 7), apart from some minor regional differences. These differences can be explained by the fact that the coupled modes reflect the co-variability of 2 different fields, while the orthogonal modes reflect the internal variability of the HI (not conditioned to the variability of a second field). However, the first coupled mode is remarkably similar to the first EOF (Figs. 5a \& 7a). The east-west contrast (Figs. 5b \& 7b), the Atlantic-Mediterranean contrast (Figs. 5c \& 7c) and the tripolar structure (Figs. 5d \& 7d), where central Europe is in phase opposition with southwestern and southeastern Europe, are also clearly apparent in the coupled modes. 

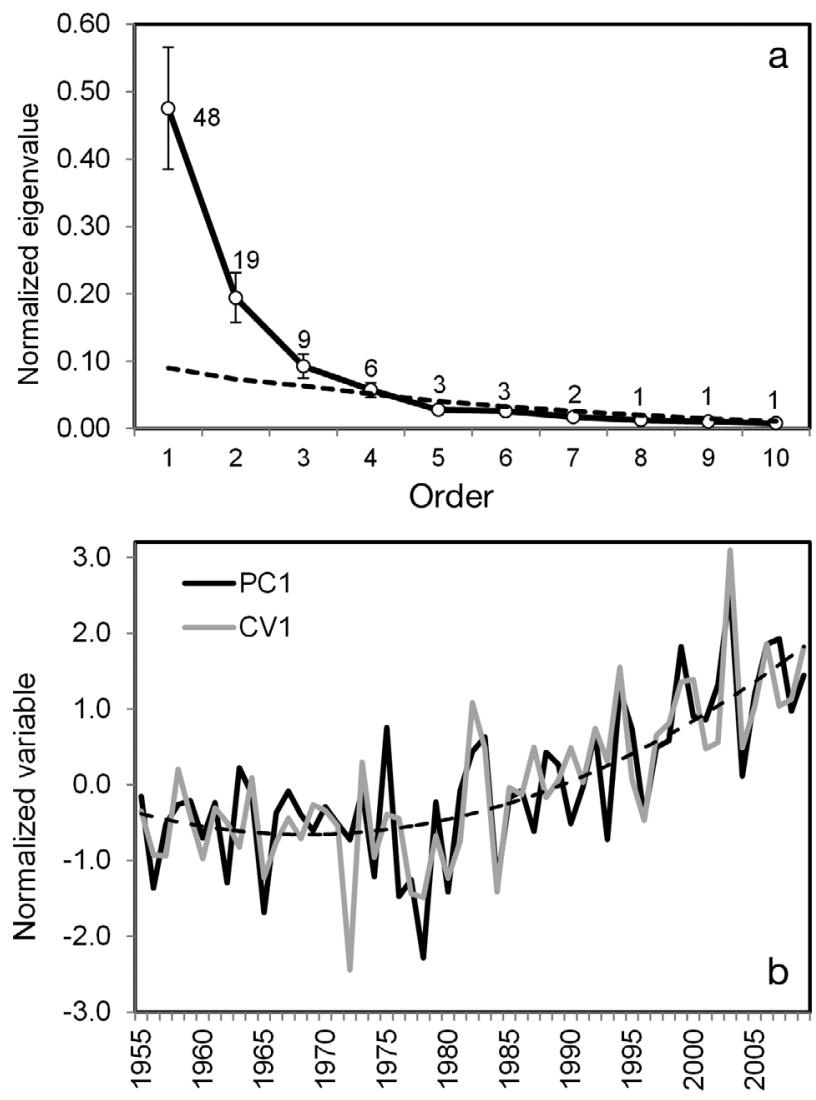

Fig. 6. (a) Eigenspectrum of the first 10 orthogonal modes of the inter-annual variability of the HI over Europe (E-OBS data set in 1955-2009); numbers in graph: respective percentages of represented variance. The 4 principal components are above the red-noise level (dashed line) and are non-degenerate (non-overlapping error bars). (b) Normalized time series of the leading principal component (PC1; black curve) and of the leading canonical variable (CV1; grey curve) between MSLP and HI. Their correlation coefficient is $r=0.84$ (statistically significant at the $99 \%$ confidence level). A second order polynomial fit to PC1 is also displayed

The first coupled mode confirms that anomalously high temperatures in Europe (Fig. 7a, left panel) tend to be associated with anomalously high $\mathrm{HI}$ values (Fig. $7 \mathrm{a}$, right panel), particularly over western Europe. In addition, the strong warming experienced during the last decades over Europe also largely explains the upward trend in this mode, which can be confirmed by the high correlation coefficient $(\mathrm{r}=$ 0.84 , statistically significant at the $99 \%$ confidence level) between the first canonical variable and the leading principal component (Fig. 6b). Therefore, the first coupled mode not only highlights that anomalously high temperatures over Europe are obviously favourable to high HI values, but also that the warming of the recent past has been contributing to an upward trend in the index itself. The other 3 coupled modes also show a close correspondence between anomalies in the mean air temperature and in the $\mathrm{HI}$ (Fig. $7 \mathrm{~b}-\mathrm{d}$ ); these associations are examined in greater depth in the subsequent analysis.

The 4 coupled modes presented above suggest there is an important large-scale atmospheric forcing on the inter-annual variability of the HI. This forcing can be more easily demonstrated by also applying the CCA to the MSLP fields, also averaged over April to September (Fig. 8); left panels in Fig. 8 represent the canonical patterns in sea level pressure and right panels represent the associated canonical patterns in the HI. In effect, the MSLP fields are a very useful tool for analysing the extratropical large-scale atmospheric flow, mostly owing to the resemblance between the actual large-scale flow and its quasigeostrophic approximation (see Holton 2004).

The first coupled mode (Fig. 8a) depicts anomalously higher pressures over Europe and lower pressures over the North Atlantic Ocean, which is favourable to producing anomalously high temperatures across Europe. The second coupled mode (Fig. 8b) shows that anomalously high pressure over northern Europe and northern Africa tends to be associated with higher $\mathrm{HI}$ in northwestern Europe and lower HI in southeastern Europe. Also, note the presence of a low pressure area westwards of the Iberian Peninsula. This pattern in the MSLP favours northerly cold winds over eastern Europe and southerly warm winds over western Europe, which explains the associated east-west contrast in both the temperature pattern and in the HI (Fig. 7b). The third coupled mode (Fig. 8c) reveals that the high pressure systems over northern Europe and northeastern Russia can prevent the transport of relatively cold air masses that originate over the North Atlantic Ocean towards Europe; this, in turn, can produce anomalously high temperatures and HI values. Maritime areas of Europe are largely exposed to these systems, whereas southeastern Europe is blocked from their direct influence, which explains the AtlanticMediterranean contrast (Figs. 7c \& 8c). Finally, the fourth coupled mode (Fig. 8d) suggests that anomalously low pressures over northeastern Europe and high pressures near the British Isles trigger the tripolar structure already identified in the inter-annual variability of the temperature and HI (Figs. $7 d$ \& 8d).

The results above highlight the advective nature of the coupled modes and clearly suggest that largescale atmospheric dynamics underlie the occurrence of the modes of variability in the $\mathrm{HI}_{i}$ these modes are not only statistically significant in explaining the observed variability in the HI pattern over Europe, 

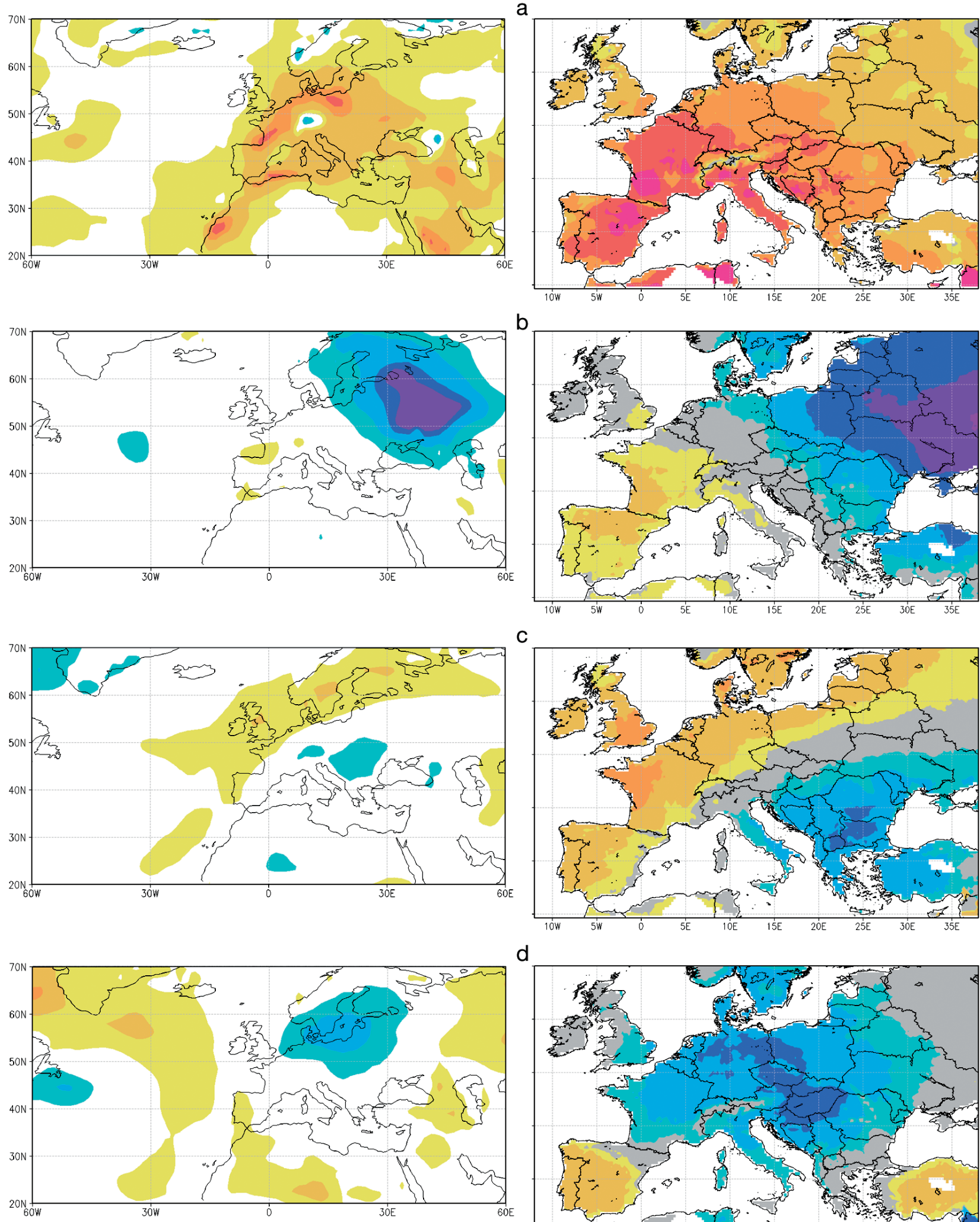

d

Temperature $\left({ }^{\circ} \mathrm{C}\right)$
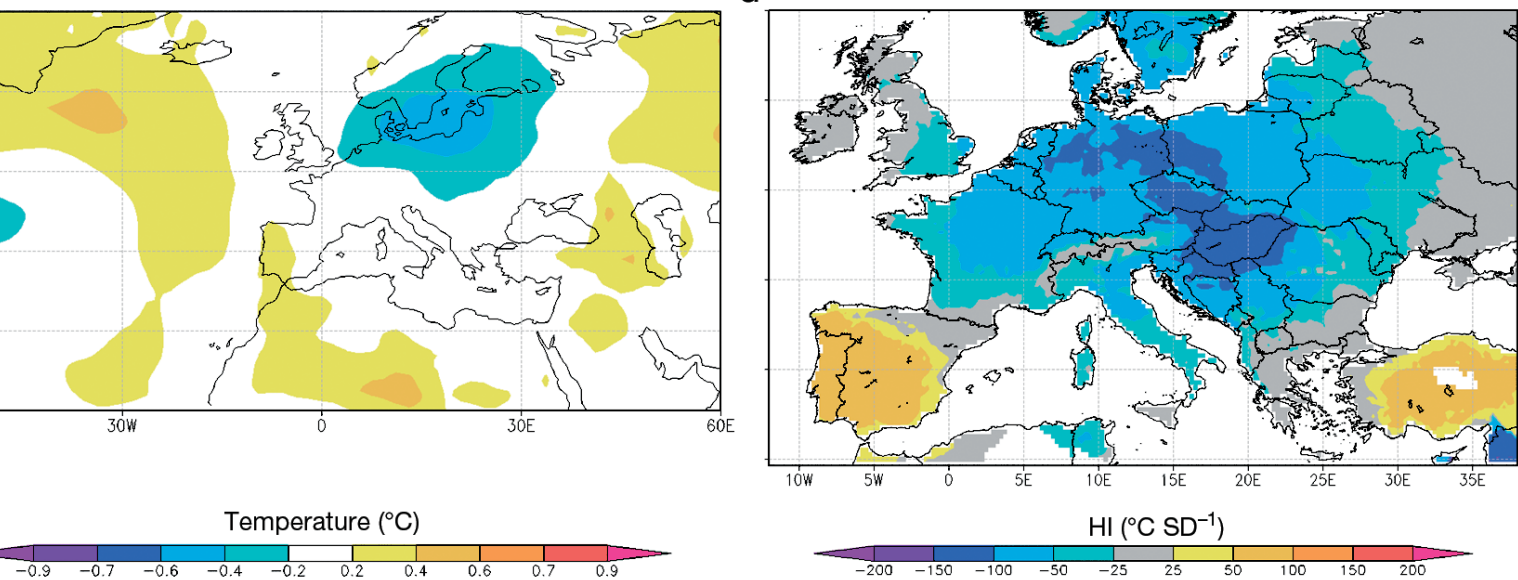

Fig. 7. Leading 4 canonical pairs (coupled modes) between the April-September averages of the $2 \mathrm{~m}$ air temperature within the Euro-Atlantic sector (left panels) and the HI in Europe (right panels) in the period 1955-2009, where SD is that of the corresponding canonical variable. Canonical correlations are 0.96, 0.91, 0.78 and 0.57 (statistically significant at $95 \%$ confidence level; Bartlett-Lawley test) 

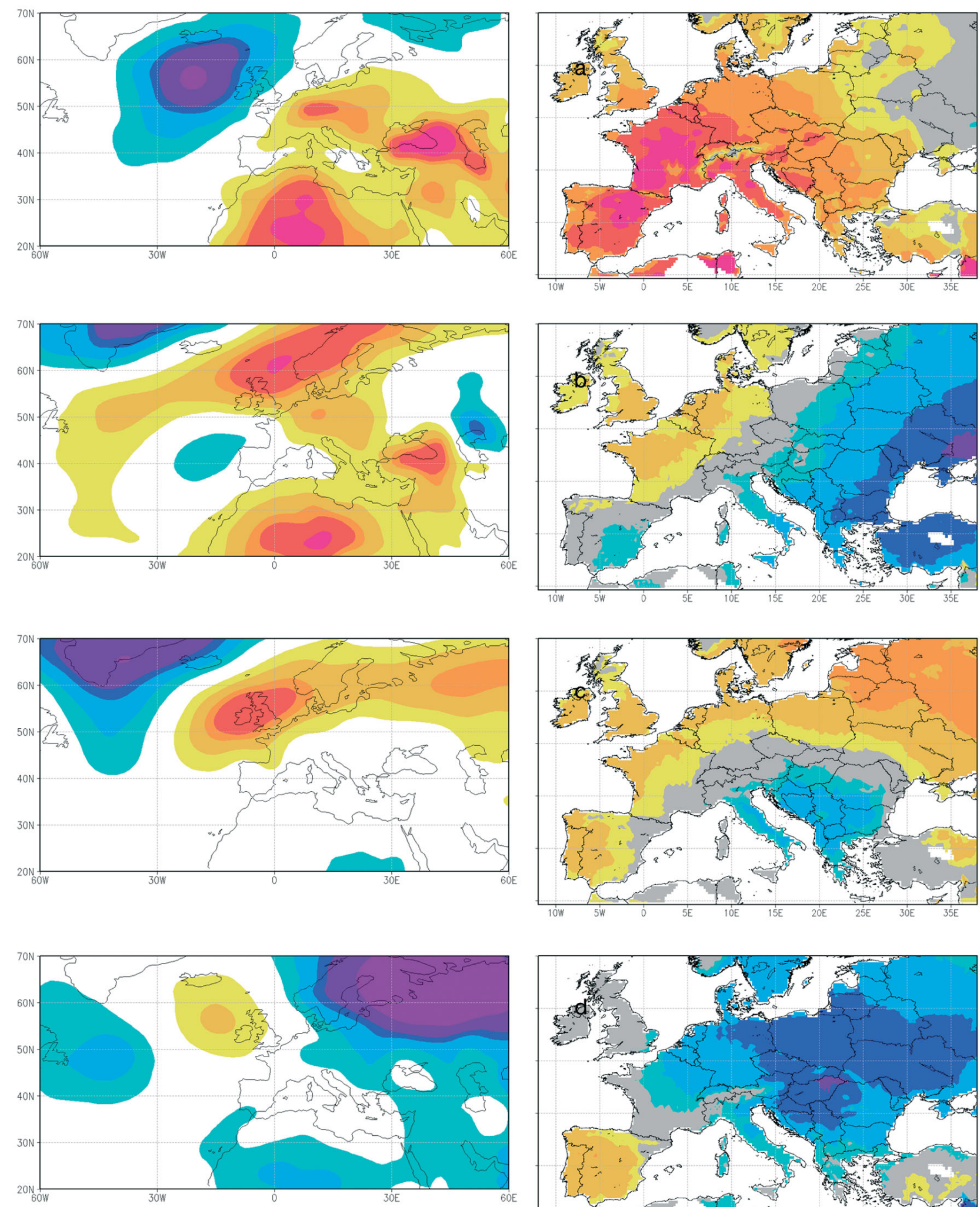

$\mathrm{SLP}\left(\mathrm{hPa} \mathrm{SD}{ }^{-1}\right)$

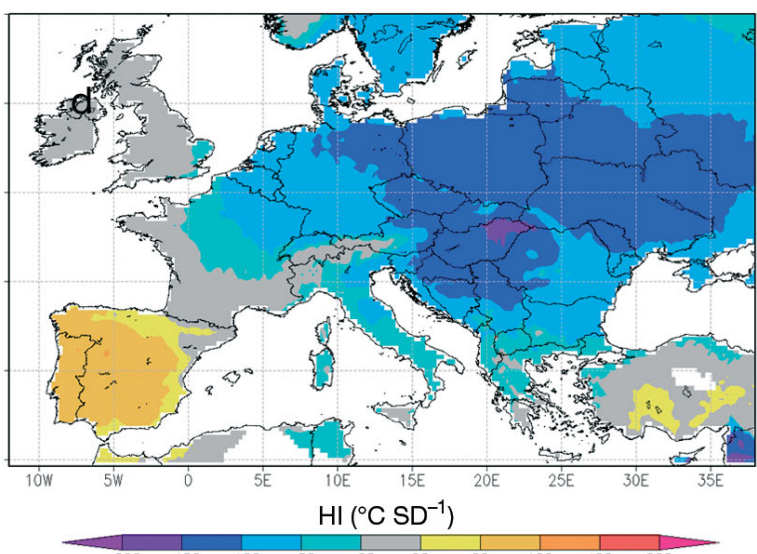

Fig. 8. The same as described in Fig. 7, but for the mean sea level pressure (SLP, left panels). Canonical correlations are $0.82,0.61,0.60$ and 0.44 (statistically significant at $95 \%$ confidence level; Bartlett-Lawley test) 
but are also physically meaningful, because they are related to large-scale anomalies in the atmospheric flow. For example, the pattern of the first mode of variability looks similar to the synoptic conditions between June and August 2003, which were dominated by an anticyclonic ridge that extended from southwestern Europe towards central Europe and was characterised by above average temperatures (e.g. Fink et al. 2004). These conditions eventually led to the summer heat wave of June to August 2003 (e.g. Beniston 2004, Schär et al. 2004).

\section{DISCUSSION AND CONCLUSIONS}

Previous studies have demonstrated the key role bioclimatic factors play in viticultural zoning for different European regions (e.g. Kenny \& Harrison 1992, Stock et al. 2005, Blanco-Ward et al. 2007, Ramos et al. 2008, Orlandini et al. 2009), but also have highlighted the relevance of the various climatic factors in governing the geographical distribution of grapevines and of their phenological development stages (e.g. Jones et al. 2005a,b). Moreover, the inter-annual variability and long-term (multi-decadal) trends in the main climatic elements, such as temperature and precipitation, are also largely reflected in the bioclimatic indices. Consequently, both climate variability and long-term trends may have strong effects on grapevine development, ultimately affecting the whole wine-producing sector (e.g. socio-economic effects). Thus, a better understanding of the mechanisms underlying the inter-annual variability and long-term trends in the bioclimatic indices is required. Hence, the aims of this study were not only to update information for viticultural zoning by using a new high-resolution data set to map bioclimatic indices over Europe, but also to analyse the interannual variability of the indices and possible longterm trends, giving particular emphasis to the largescale atmospheric forcing.

Nine bioclimatic indices for viticultural zoning were selected and were computed for Europe in the period from 1950 to 2009 by using a state-of-the-art observational data set (E-OBS). Their mean spatial patterns (Figs. 1-4) reflect a strong climatic heterogeneity throughout Europe, which explains the large diversity of grapevine varieties grown in Europe that leads to the large number of different wine styles produced across the continent. The high spatial resolution of these patterns provides detailed and updated information for viticultural zoning in Europe, which accomplishes the first aim of this study. Further, the analysis of different indices enriches this study by providing different perspectives on the influence of climate on viticulture.

The analyses of the inter-annual variability and trends also illustrate significant regional differentiations (Figs. 3-8). Significant upward trends are identified for the WI and HI, particularly for southwestern Europe. In accordance with Jones et al. (2005b), trends of 100 to 300 units for the HI and WI over the second half of the twentieth century were found. These trends are mostly a result of warming during the growing season, but are more significant in both indices owing to the summation of positive temperature anomalies in their formulations. In terms of interannual variability, 4 statistically significant orthogonal modes of variability are isolated for the HI, jointly representing $82 \%$ of the total variance in Europe. The leading mode explains $48 \%$ of the variance and mainly reflects the observed historical trends discussed here. The second mode is a manifestation of a west-east contrast in the variability over Europe (19\% of the variance). The third mode mostly depicts a contrast between the Atlantic and Mediterranean areas ( $9 \%$ of the variance). The fourth mode presents a tri-polar structure, where central Europe is in phase opposition with southwestern and southeastern Europe ( $6 \%$ of the variance). As shown by applying the $\mathrm{CCA}$, these modes in the $\mathrm{HI}$ and WI are mainly forced by the mean large-scale atmospheric circulation during the growing season (April-September), mostly by advective mechanisms, and achieve the second aim of the present study.

The identified large-scale couplings show little resemblance to the most relevant teleconnection indices within the Euro-Atlantic sector (Wallace \& Gutzler 1981). There is some similarity between the first coupled mode identified in this study and the Eastern Atlantic Oscillation (EAO; strong center of action westwards of the British Isles), which has important effects on the atmospheric circulation over the North Atlantic Ocean and Europe, particularly western Europe (e.g. Woollings et al. 2010). The fourth coupled mode also suggests some linkage to the Scandinavian pattern (strong center of action over Scandinavia, Barnston \& Livezey 1987), though the geographic window is not sufficiently large to establish a clear relationship. Finally, a possible minor role from the El Niño Southern Oscillation (ENSO) is hard to differentiate from the effects of the NAO (Rodó \& Comín 2000). Despite the significance that local and regional climatic and meteorological effects have on grapevine growth, productivity and quality, the present study demonstrates that large-scale atmospheric 
features play a central role in determining the viticultural suitability of a particular year at a given location in Europe.

The results from this analysis point to potential areas of future research, namely, (1) the development of operational tools for the timely prediction of grapevine growth and composition parameters (e.g. using seasonal forecasts for regional circulation characteristics to assess temperature and precipitation effects on bioclimatic indices), and (2) a better assessment of the socio-economic effects of climate change on viticulture. Under future climate conditions (IPCC SRES B1 and A1B), potential shifts in European areas suitable for wine production northwards and/or to higher elevations are projected to occur (Malheiro et al. 2010). Furthermore, traditional rain-fed areas in southern Europe may have to adopt irrigation practices to maintain production at current levels. These results are even more important given the recent finding that increased summer dryness in southern Europe will probably further restrict plant growth and survival, causing a positive warming feedback effect through reduced evapotranspiration (Wramneby et al. 2010). Therefore, the climate change projections detailed by Malheiro et al. (2010) largely agree with the historical trends described herein (Fig. 4b) and the work of others. In this manner, the documented effects of the historical trends are, to a certain extent, a valuable indicator of what could be expected in the future. In fact, adding historical records of grapevine phenological stages and wine production data should significantly improve the assessment of the effects of these future projections in bioclimatic indices, which are so important for understanding viticultural suitability.

Acknowledgements. We acknowledge the E-OBS data set from the EU-FP6 project ENSEMBLES (http://ensembleseu.metoffice.com) and the data providers in the ECA\&D project (http://eca.knmi.nl). We also acknowledge the Physical Sciences Division at the NOAA/ESRL for providing data from the NCEP/NCAR Reanalysis Project. We also thank the anonymous reviewers for their valuable comments.

\section{LITERATURE CITED}

Amerine MA, Winkler AJ (1944) Composition and quality of musts and wines of California grapes. Hilgardia 15: 493-675

> Barnett TP, Preisendorfer R (1987) Origins and levels of monthly and seasonal forecast skill for United States surface air temperatures determined by canonical correlation analysis. Mon Weather Rev 115:1825-1850

Barnston AG, Livezey RE (1987) Classification, seasonality and persistence of low-frequency atmospheric circulation patterns. Mon Weather Rev 115:1083-1126

Beniston M (2004) The 2003 heat wave in Europe: a shape of things to come? An analysis based on Swiss climatological data and model simulations. Geophys Res Lett 31: 2022-2026

Bindi M, Fibbi L, Gozzini B, Orlandini S, Miglietta F (1996) Modelling the impact of future climate scenarios on yield and yield variability of grapevine. Clim Res 7:213-224

Blanco-Ward D, Queijeiro JMG, Jones GV (2007) Spatial climate variability and viticulture in the Miño River Valley of Spain. Vitis 46:63-70

Branas J, Bernon G, Levadoux L (1946) Eléments de viticulture générale. Imp Dehan, Montpellier

Bretherton CS, Smith C, Wallace JM (1992) An intercomparison of methods for finding coupled patterns in climate data. J Clim 5:541-560

dos Santos TP, Lopes CM, Rodrigues ML, de Souza CR and others (2003) Partial rootzone drying: effects on growth and fruit quality of field grown grapevines (Vitis vinifera). Funct Plant Biol 30:663-671

Esteves MA, Orgaz MDM (2001) The influence of climatic variability on the quality of wine. Int $\mathrm{J}$ Biometeorol 45: 13-21

Fink AH, Brücher T, Krüger A, Leckebusch GC, Pinto JG, Ulbrich U (2004) The 2003 European summer heat waves and drought - synoptic diagnosis and impacts. Weather 59:209-216

Grifoni D, Mancini M, Maracchi G, Orlandini S, Zipoli G (2006) Analysis of Italian wine quality using freely available meteorological information. Am J Enol Vitic 57: 339-346

> Haylock MR, Hofstra N, Klein Tank AMG, Klok EJ, Jones PD, New M (2008) A European daily high-resolution gridded dataset of surface temperature and precipitation. J Geophys Res 113:D20119 doi:10.1029/2008JD010201

Hidalgo L (2002) Tratado de viticultura general. Ediciones Mundi-Prensa, Madrid

Holton JR (2004) An introduction to dynamic meteorology, 4th edn. Elsevier Academic Press, New York

Huglin P (1978) Nouveau mode d'évaluation des possibilités héliothermiques d'un milieu viticole. CR Acad Agric Fr 64:1117-1126

Jones GV (1997) A synoptic climatological assessment of viticultural phenology. PhD dissertation, University of Virginia

Jones GV (2006) Climate and terroir: impacts of climate variability and change on wine. In: Macqueen RW, Meinert LD (eds) Fine wine and terroir. The geoscience perspective. Geosci Can Repr Ser 9. Geological Association of Canada, St. John's

Jones GV, Davis RE (2000a) Climate influences on grapevine phenology, grape composition, and wine production and quality for Bordeaux, France. Am J Enol Vitic 51: 249-261

> Jones GV, Davis RE (2000b) Using a synoptic climatological approach to understand climate/viticulture relationships. Int J Climatol 20:813-837

Jones GV, White MA, Cooper OR, Storchmann K (2005a) Climate change and global wine quality. Clim Change 73: 319-343

Jones GV, Duchêne E, Tomasi D, Yuste J and others (2005b) Changes in European winegrape phenology and relationships with climate. In: Proceedings of the Groupe d'Etude des Systèmes de Conduite de la vigne (GESCO 
2005), Geisenheim

Jones GV, Duff AA, Hall A, Myers JW (2010) Spatial analysis of climate winegrape growing regions in the Western United States. Am J Enol Vitic 61:313-326

Kenny GJ, Harrison PA (1992) The effects of climate variability and change on grape suitability in Europe. J Wine Res 3:163-183

Kistler R, Collins W, Saha S, White G, Woollen J (2001) The NCEP-NCAR 50-year reanalysis: monthly means CD-ROM and documentation. Bull Am Meteorol Soc 82: 247-267

Kliewer WM, Torres RE (1972) Effect of controlled day and night temperatures on grape coloration. Am J Enol Vitic 23:71-77

Koundouras S, van Leeuwen C, Seguin G, Glories Y (1999) Influence de l'alimentation en eau sur la croissance de la vigne, la maturation des raisins et les caractéristiques des vins en zone méditerranéenne (exemple de Némée, Grèce, cépage Saint-Georges, 1997). J Int Sci Vigne Vin 33:149-160

Magalhães NP (2008) Tratado de viticultura — a videira, a vinha e o 'terroir'. Chaves Ferreira Publicações, Lisboa

Malheiro AC, Santos JA, Fraga H, Pinto JG (2010) Climate change scenarios applied to viticultural zoning in Europe. Clim Res 43:163-177

North GR, Bell TL, Cahalan RF (1982) Sampling errors in the estimation of empirical orthogonal functions. Mon Weather Rev 110:699-706

Orlandini S, Stefano V, Lucchesini P, Puglisi A, Bartolini G (2009) Current trends of agroclimatic indices applied to grapevine in Tuscany (Central Italy). Id járás (Q J Hung Meteorol Soc) 113:69-78

Ramos MC (2006) Soil water content and yield variability in vineyards of Mediterranean northeastern Spain affected by mechanization and climate variability. Hydrol Process 20:2271-2283

Ramos MC, Jones GV, Martínez-Casasnovas JA (2008) Structure and trends in climate parameters affecting winegrape production in northeast Spain. Clim Res 38:1-15

Riou C, Becker N, Sotés Ruiz V, Gomez-Miguel V and others (1994) Le déterminisme climatique de la maturation du raisin: application au zonage de la teneur en sucre dans la communauté européenne. Office des Publications Officielles des Communautés Européennes, Luxembourg

Rodó X, Comín FA (2000) Links between large-scale anomalies, rainfall and wine quality in the Iberian Peninsula during the last three decades. Glob Change Biol 6: 267-273

Santos JA, Corte-Real J (2006) Temperature extremes in Europe and large-scale circulation: HadCM3 future scenarios. Clim Res 31:3-18

Santos JA, Corte-Real J, Ulbrich U, Palutikof J (2007) European winter precipitation extremes and surface largescale circulation: a coupled model and its scenarios.
Theor Appl Climatol 87:85-102

Santos JA, Malheiro AC, Karremann MK, Pinto JG (2011) Statistical modelling of grapevine yield in the Port Wine region under present and future climate conditions. Int $\mathrm{J}$ Biometeorol 55:119-131

Schär C, Vidale PL, Lüthi D, Frei C, Häberli C, Lininger MA, Appenzeller C (2004) The role of increasing temperature variability in European summer heatwaves. Nature 427: 332-336

> Schultz HR (2000) Climate change and viticulture: a European perspective on climatology, carbon dioxide and UVB effects. Aust J Grape Wine Res 6:2-12

> Souriau A, Yiou P (2001) Grape harvest dates for checking NAO paleoreconstructions. Geophys Res Lett 28: 3895-3898

Stock M, Gerstengarbe FW, Kartschall T, Werner PC (2005) Reliability of climate change impact assessments for viticulture. Proceedings of the VII international symposium on grapevine physiology and biotechnology. Acta Hortic 689:29-39

Tonietto J, Carbonneau A (2004) A multicriteria climatic classification system for grape-growing regions worldwide. Agric Meteorol 124:81-97

Trenberth KE, Jones PD, Ambenje P, Bojariu R and others (2007) Observations: surface and atmospheric climate change. In: Solomon S, Qin D, Manning M, Marquis M and others (eds) Climate change 2007: the physical science basis. Contribution of Working Group I to the Fourth Assessment Report of the Intergovernmental Panel on Climate Change. Cambridge University Press, Cambridge, p 235-336

van Leeuwen C, Friant P, Choné X, Tregoat O, Koundouras S, Dubourdieu D (2004) Influence of climate, soil, and cultivar on terroir. Am J Enol Vitic 55:207-217

von Storch H, Zwiers FW (1999) Statistical analysis in climate research. Cambridge University Press, Cambridge

Wallace JM, Gutzler DS (1981) Teleconnections in the geopotential height field during the Northern Hemisphere winter. Mon Weather Rev 109:784-812

> Wanner H, Brönnimann S, Casty C, Gyalistras D, Luterbacher J, Schmutz C, Stephenson DB, Xoplaki E (2001) North Atlantic Oscillation-concepts and studies. Surv Geophys 22:321-382

Wilks DS (2006) Statistical methods in the atmospheric sciences. International Geophysics Series. Elsevier, New York

Winkler AJ, Cook JA, Kliwer WM, Lider LA (1974) General viticulture. University of California Press, Berkeley, CA

Woollings T, Hannachi A, Hoskins B (2010) Variability of the North Atlantic eddy-driven jet stream. Q J R Meteorol Soc 136:856-868

Wramneby A, Smith B, Samuelsson P (2010) Hot spots of vegetation-climate feedbacks under future greenhouse forcing in Europe. J Geophys Res 115:D21119

Submitted: March 1, 2011; Accepted: September 24, 2011

Proofs received from author(s): February 2, 2012
Editorial responsibility: Gerrit Hoogenboom,

Prosser, Washington, USA 